\title{
POSITIVE EFFECTS OF ENTERTAINMENT TECHNOLOGY ON HUMAN BEHAVIOUR
}

\author{
Matthias Rauterberg \\ Technical University Eindhoven (The Netherlands)
}

\begin{abstract}
Worldwide the pros and cons of games and social behaviour are discussed. In Western countries the discussion is focussing on violent game and media content; in Japan on intensive game usage and the impact on the intellectual development of children. A lot is already discussed on the harmful and negative effects of entertainment technology on human behaviour, therefore we decided to focus primarily on the positive effects. Based on an online document search we could find and select 393 online available publications according the following categories: meta review $(\mathrm{N}=34)$, meta analysis $(\mathrm{N}=13)$, literature review $(\mathrm{N}=38)$, literature survey $(\mathrm{N}=36)$, empirical study $(\mathrm{N}=91)$, survey study $(\mathrm{N}=44)$, design study $(\mathrm{N}=91)$, any other document $(\mathrm{N}=46)$. In this paper a first preliminary overview over positive effects of entertainment technology on human behaviour is presented and discussed. The drawn recommendations can support developers and designers in entertainment industry.
\end{abstract}

Key words: Meta review, entertainment, positive effect, behaviour, recommendations.

\section{INTRODUCTION}

This paper focuses on users' growing use of entertainment technology at work, in school and at home, and the impact of this technology on their behaviour. Nearly every working and living place has computers, and over two-thirds of children in high industrialized countries have computers in their homes as well [7] [12]. All of us would probably agree that adults and children (normal, impaired and disabled) need to become competent users to be prepared for life and work in the future. Especially children's growing use of entertainment technologies brings with it both the risk of possible harm and the promise of enriched learning, well-being and positive development. Entertainment technology covers a broad range of products and services: 
movie, music, TV (including upcoming interactive TV), VCR, VOD (including music on demand), computer game, game console, video arcade, gambling machine, internet (e.g. chat room, board and card games, MUD), intelligent toy, edutainment, simulation, VR, and upcoming service robots [2] [21] [24] [30].

\section{META REVIEW APPROACH}

This paper presents the preliminary results of a literature search and review. We searched for the following keywords (context specific in different combinations): 'academic achievement, altruism, ANOVA, attainment, children, computer, education, edutainment, entertainment, gamble, game, meta analysis, PDF, performance, pet, positive effect, religion, robot, school record, review, survey, technology, therapy, user study, video', using the following search engines/databases: 'ACM Digital Library, IEEE Computer Society Digital Library, Internet via Google, ISI web of science, Kluwer online, LookSmart, Prenctice Hall, Science Direct, Scirus for scientific information, SpringerLink, Wiley interScience'. We could find, select and process 393 online available publications (e.g. DOC, RTF, PDF or HTML format) according the following categories: meta review $(\mathrm{N}=34)$, meta analysis $(\mathrm{N}=13)$, literature review $(\mathrm{N}=38)$, literature survey $(\mathrm{N}=36)$, empirical study $(\mathrm{N}=91)$, survey study $(\mathrm{N}=44)$, design study $(\mathrm{N}=91)$, any other document $(\mathrm{N}=46)$ (for a complete reference list see [27]). The preliminary and selective results presented in this paper summarize research so far available on how the use of entertainment technology affects human's daily life in a positive and promising manner.

\section{GENERAL REMARKS}

It has to be pointed out that addiction, racism, sexism, violence, etc are not new inventions of the entertainment and game industry and would not disappear from the world, where games abolished. They should better be seen as a reflection of underlying dimensions of a society or culture into economical and social accepted artifacts [6]. In this respect a criticism of games can not be separated from a fundamental critique of the society which produce, accept and promote these games. It could be shown [35] that misunderstanding is endemic in the Western culture because most of the Western societies tend to believe that the best way to a common goal is by rigorous and often aggressive dispute. There for a lot confrontational public forums are established, from congressional politics to media hearings. The author argues that thoughtful debate and real understanding gets lost in all 
these disputes. She suggests to consider other methods of communication and offers a survey of mostly non-Western ways of dealing with conflict, including the use of intermediaries and rituals.

It is our responsibility as researchers, engineers, politicians, parents and educators to pay attention to all relevant issues, and to discuss them in the proper context of references and values, so that entertainment industry can be enabled to make correct choices for their future developments (see e.g. [2] [11] [23]). How can we get an appropriate orientation, given the fact that controversial discussions take place (see [1] [7] [13] [14] [32])?

\section{RESULTS AND RECOMMENDATIONS}

\subsection{EFFECTS IN EDUCATIONAL CONTEXT}

Academic performance: In a research program the use of electronic communication and games with children was investigated in both classroom and after-school settings for nearly 15 years [9]. The after-school programs was called "The Fifth Dimension", and include the typical uses of home computers, such as educational software, computer games, searching the Internet, and multi-user dungeons (MUD) activities. Subject matter includes social development, geography, communications, reading, writing, math, social studies, health, technology, language, and problem solving. The computer games and Internet activities are based in a social and cognitive context that includes a ladder of challenges [25]. This research program effects include advances in reading [31] and mathematics [8] [10], computer knowledge, following directions, grammar and school achievement tests [9].

A considerable body of research has examined the effects of computer use on academic performance. Reviews of this literature typically conclude that the results are preliminary (e.g., [29], [33]). Although benefits of computer use have been observed, they typically depend on a variety of factors (mainly on context of use and content). The only positive cognitive effect have been consistently observed is visual-spatial skills. Gaming in 2D or 3D applications contributes to visual-spatial skills, at least when these skills are assessed immediately after the computer activity [34].

General development: Games require the use of logic, memory, problem solving and critical thinking skills, visualization and discovery [34]. Their use requires that players manipulate objects using electronic tools and develop an understanding of the game as a complex system. Play is an effective teaching strategy both inside and outside school. According to "Goldstein more than 40 studies concludes that play enhances early development by at least 33\%" [36]. Play with games and toys are an important part of child development to acquire a variety of skills for life, such as motor- 
coordination, social and cognitive skills [15]. As societies become increasingly concerned about the physical and psychological well-being of children, the value of playing and learning is getting crucial [22]. Players can progress from newcomer to expert, in particular in belonging to a social system [11].

Play: People who have been allowed and encouraged to play stand the best chance of becoming healthy, happy and productive members of society [33]. Some positive aspects of playing can promote literacy, thinking, reflecting and creativity [16] [31].

Teaching: If computer games are to become part of educational settings, it is crucial to question existing stereotypes and to ensure that the culture of games players in education conforms to neither [13]. It is teachers' stereotypes that resist change and not people; therefore, by interrogating conceptions of these stereotypes it is possible to avoid falling into the error of believing them to be exclusive descriptors of games players [11].

\subsection{EFFECTS ON SOCIAL BEHAVIOUR}

Collaboration: Collaborative game playing necessitates the development of social skills, for example in order to decide on, define and agree goals. All of these features should be usefully incorporated into next generation of computer games that will support positive effects on the social and intellectual development of the users. In a meta-analysis study [17] 122 empirical studies on the effect of competition on result of players' improvement are reviewed. This meta-analysis included every study that could be found on achievement in (a) co-operative, (b) competitive and/or (c) individualistic tasks (not only games and play). 65 studies found that (a) co-operation tasks promotes higher achievement than (b) competitive tasks, 8 found the reverse, and 36 found no statistically significant difference. Co-operation tasks promoted higher achievement than (c) individualistic tasks in 108 studies, while 6 found the reverse, and 42 found no difference. The superiority of cooperation could be justified for higher achievement for all subject areas and all age groups [17] (see also [18]).

Prosocial behaviour: The results of a meta analysis about positive effects of television on social behaviour indicate clearly that prosocial content of entertainment technology does have positive effects as follows [20]: “(1) Children exposed to prosocial content have more positive social interactions, show more altruistic behavior and self-control, and have less stereotyped views of others. (2) The strongest effects of prosocial content were found for measures of altruism. (3) Relying on children's ability to pick out the moral messages from programs which feature violence or conflict and some prosocial resolution may backfire, leading to more aggression than merely showing the conflict. (4) Effects of prosocial content are often strongest when 
viewing is combined with discussion. (5) The effect sizes overall ranged from small to medium. (6) Effects of prosocial content were strongest for pre-school and grade-school children, diminishing in adolescence. (7) Effects are somewhat stronger for girls than for boys" (p. 19). In a more recent literature review the following results are presented [34]: (1) "game playing did not impact the social network and characteristics of interactions among children" (p. 17); (2) "socially anxious and lonely people find more honest and intimate human relationships with others on the Internet than in the real world, and they tend to successfully integrate these online relationships into their offline lives" (p. 20).

Recommendations: Cole's results [9] indicate that well designed computer games and Internet activities for home use can have a lasting positive impact on children's academic performance. The design of entertainment product should focus on prosocial and altruistic content (e.g. Tamagotchi [4], Robota [3], Kismet [5], Affect-Support Agent [19]). Based on the results of Johnson's meta-analysis co-operative entertainment systems are strongly recommended [17]. The results of an experimental study show that separated audio communication line per team should be provided to increase cooperation among team members [26].

\subsection{THERAPEUTIC EFFECTS}

Health Care: The introduction of the 'mental commit' robot pet Paro in a hospital environment showed promising results: the mood of children and elderly patients could be positively changed [23]. Turnin et al [38] could find a positive influence of a computer game on 2000 children for nutritional teaching. "In conclusion, it is possible for children to learn good eating habits by playing computer games" (p. 239).

Hyperactivity: Early research suggests that active play may reduce impulsivity thereby helping children with attention deficit and hyperactivity disorder (ADHD, see [37]). Goldstein concludes [14] that play is of fundamental importance to children, but it is not always recognized and fully appreciated by adults and society. Playing is fun and contributes to children's happiness, but it is also vital to their health and well-being.

Phobia: Using a low-cost commercial computer game VR application with head mounted display applied to phobic and non-phobic persons resulted in a sufficient amount of immersion and presence for the phobic patients to be useful for therapeutic settings [28].

Recommendations: "The phobogenic effectiveness of the inexpensive hardware and software used in this study shows that VR technology is sufficiently advanced for VR exposure therapy to move into the clinical mainstream" ([28] p. 475). The authors conclude that low cost, therapeutic VR 
applications based on desktop VR games are superior to their expensive commercial counterparts. Mental commit robots and computer games with proper content have positive health effects as well.

\section{CONCLUSIONS}

So far, two main conclusions can be drawn: (1) not the technology in its self, but the content of the product or service really matters, (2) the context of use is almost as important as the content. If the content and the context of use is properly designed, positive effects on the users can be achieved. The following contents and contexts of use can maximize positive effects on human behaviour of different age (children, adults, elderly): prosocial content, game like computer aided instructions/learning application, robot pets, in a multi-user, collaborative or therapeutic setting.

\section{REFERENCES}

[1] Anderson, C. \& Bushman, B. (2002). Effects of media violence on society. Science, Vol. 295, No. 3, pp. 2377-2379.

[2] Berman, S. (2004). Media and entertainment 2010. Report, IBM Business Consulting Sevices.

[3] Billard, A. (2003). Robota: clever toy and educational tool. Robotics and Autonomous Systems, Vol. 42, pp. 259-269.

[4] Bloch, L.-R. \& Lemish, D. (1999). Disposable love, new media \& society, Vol. 3, pp. 283-303.

[5] Breazeal, C. (2003). Toward sociable robots. Robotics and Autonomous Systems, Vol. 42, pp. 167-175.

[6] Breuer, H. (2001). Kultivation und Imagination in den neuen Medien [Cultivation and imagination in new media]. PhD Thesis, O.-v.-G.-Universität Magdeburg, Germany.

[7] Calvert, S., Jordan, A.B. \& Cocking, R.R. (2002). Children in the digital age: the role ofentertainment technologies in children's development, Praeger Publishers.

[8] Clements, D. H. (2000). From exercises and tasks to problems and projects - unique contributions of computers to innovative mathematics education. Journal of Mathematical Behavior, Vol. 19, No. 1, pp. 9-47.

[9] Cole, M. (1996). Cultural psychology: a once and future discipline. Harvard Press.

[10] Cox, M. \& Abbott, M. (2004, eds.). A review of the research literature relating to ICT and attainment. Report, retrieved April 27, 2004 from www.becta.org.uk

[11] Cox, M. \& Webb, M. (2004, eds.). An investigation of the research evidence relating to ICT pedagogy. Report, retrieved April 27, 2004 from www.becta.org.uk

[12] Durkin, K. \& Aisbett, K. (1999). Computer Games and Australians today. Report, Office of Film and Literature Classification, Sydney, Australia.

[13] Garthwait, A. (2001). Factors influencing technology's effect on student achievement and a caution about reading the research. Occasional Paper No. 40, a publication of the College of Education \& Human Development, University of Maine, USA.

[14] Goldstein, J. (2000). Effects of electronic games on children. Testimonial Statement to US senate committee on Commerce, Science and Transportation, March 2000, USA. 
[15] Goldstein, J. \& Raessens, J. (2004, in press). Handbook of computer game studies. Cambridge, MA: MIT Press.

[16] Hartung, P. J. (2002). Development through work and play. Journal of Vocational Behavior, Vol. 61, pp. 424-438.

[17] Johnson, D. W., Maruyama, G., Johnson, R.T., Nelson, D., \& Skon, L. (1981). Effects of co-operative, competitive and individualistic goal structures on achievement: A metaanalysis. Psychological Bulletin, Vol. 89, pp. 47-62.

[18] Kerlin, B A. (1992). Cognitive engagement style-self regulated learning and cooperative learning. Retrieved April 27, 2004 from http://kerlins.net/bobbi/research/myresearch/srl/

[19] Klein, J., Moon, Y. \& Picard, R. (2002). This computer responds to frustration: theory, design, results and implications. Interacting with Computers, Vol. 14, pp. 119-140.

[20] Mares, M.-L. (1996). Positive effects of television on social behavior: a meat analysis. Report Series No. 3, The Annenberg Public Policy Center, Pennsylvania, USA.

[21] Nakatsu, R. \& Hoshino, J. (2003; eds.). Entertainment computing-technologies and applications. Kluwer Academic Press.

[22] National Science Foundation (2001). The application and implications of information technologies in the home: where are the data and what do they say? Report No. NSF 01313, Division of Science Resources Studies, USA.

[23] No author (2003). Therapeutic robot. AIST Today International Edition, No. 9, pp. 2-3.

[24] Pek, Z. (2003). What is entertainment technology? A short overview. Online document retrieved May 7, 2004 from www.nb2bc.co.uk/pdfs/entertaintech.pdf

[25] Priest, J., Coe, R., Evershead, B. \& Bush, N. (2004). An exploration of the use of ICT at the millennium primary school, Greenwich. Report available at www.becta.org.uk

[26] Rauterberg, M. (2003). Determinantes for collaboration in networked multi-user games. In: R. Nakatsu \& J. Hoshino (eds.), Entertainment computing-technologies and applications (pp. 313-321). Kluwer Academic Press

[27] Rauterberg, M. (2004). Entertainment technology and human behaviour: complete reference list. Report, Industrial Design, Technical University Eindhoven, Netherlands.

[28] Robillard, G., Bouchard, S., Fournier, T. \& Renaud, P. (2003). Anxiety and presence during VR immersion: a comparative study of the reactions of phobic and non-phobic participants in therapeutic virtual environments derived from computer games. CyberPsychology \& Behavior, Vol. 6, No. 5, pp. 467-477.

[29] Roschelle, J. M., Pea, R. D., Hoadley, C. M., Gordon, D. N., \& Means, B. M. (2000). Changing how and what children learn in school with computer-based technologies. Children and Computer Technology, Vol. 10, No. 2, pp. 76-101.

[30] Rose, B. \& Lenski, J. (2003). Internet and multimedia 10: the emerging difital consumer. Report, Arbitron Internet broadcast Services \& Edison Media Research.

[31] Saracho, O. N. \& Spodek, B. (1998). A play foundation for family literacy. International Journal of Educational Research, Vol. 29, pp. 41-50.

[32] Shields, M. \& Behrmann, R. (2000). Children and computer technology: analysis and recommendations. Children and Computer Technology, Vol. 10, No. 2, pp. 4-30.

[33] Subrahmanyam, K., Kraut, R. E., Greenfield, P. M. \& Gross, E. F. (2000). The impact of home computer use on children's activities and development. Children and Computer Technology, Vol. 10, No. 2, pp. 123-144.

[34] Subrahmanyam, K., Greenfield, P. M., Kraut, R. E. \& Gross, E. F. (2001). The impact of computer use on children's and adolescents' development. Applied Developmental Psychology, Vol. 22, pp. 7-30.

[35] Tannen, D. (1999). The Argument Culture: Stopping America's war ofwords. Ballantine 
[36] Toy Industries of Europe (2004). Play as key to child development as formal education. Press Release, Retrieved May 7, 2004 from www.tietoy.org/press/Nuremberg_VoP_ Seminar_English.pdf

[37] Tuchman, R. (2000). The treatment of learning disabilities. International Pediatrics, Vol. 15, No. 2, pp. 91-96.

[38] Turnin, M.C., Couvaras, O., Jouret, B., Tauber, M. T., Bolzonella, C., Fabre, D., Tauber, J. P. \& Hanaire-Broutin, H. (2000). Learning good eating habits playing computer games at school: a 2000 children evaluation. Diabetes Research and Clinical Practice, Vol. 50, No. 1001, p. 239. 